\title{
Improved lumped model for thermal analysis of high burn-up nuclear fuel rods
}

\author{
Auro C. Pontedeiro ${ }^{a}$, Renato M. Cotta ${ }^{\mathrm{b}}$, Jian $\mathrm{Su}^{\mathrm{c}, *}$ \\ ${ }^{a}$ Reactor Department, Comissão Nacional de Energia Nuclear (CNEN), Rua General Severiano 90, Botafogo, Rio de Janeiro 22290-901, Brazil \\ ${ }^{\mathrm{b}}$ Mechanical Engineering Department, POLI/COPPE, Universidade Federal do Rio de Janeiro, CP 68503, Rio de Janeiro 21941-972, Brazil \\ ${ }^{\mathrm{c}}$ Nuclear Engineering Department, COPPE, Universidade Federal do Rio de Janeiro, CP 68509, Rio de Janeiro 21941-972, Brazil
}

\begin{abstract}
High burn-up nuclear fuel elements have been intensively studied for prolonged lifetime of existing reactors and for next-generation advanced reactors. This paper presents an improved lumped-differential formulation for one-dimensional transient heat conduction in a heat generating cylinder with temperature-dependent thermo-physical properties typical of high burn-up nuclear fuel rods. Two-points Hermite approximations for integrals $\left(H_{1,1} / H_{1,1}\right)$ were used to obtain the average temperature and heat flux in the radial direction. As a testing case, transient heat conduction in a nuclear fuel rod was computed with the thermo-physical properties represented by the MATPRO correlations. The problem was formulated and solved by using the symbolic/numerical computation software system MATHEMATICA. The solutions of the proposed improved lumped model were validated by comparing with numerical solutions of the original distributed parameter formulation of the transient heat conduction problem, as well as by comparing with simulation results of a cold leg SBLOCA with RELAP5/MOD3.
\end{abstract}

(C) 2008 Elsevier Ltd. All rights reserved.

Keywords: Nuclear fuel rods; High burn-up; Transient heat conduction; Lumped model; Nonlinear diffusion problem

\section{Introduction}

High burn-up nuclear fuel elements have been intensively studied for prolonged lifetime of existing reactors and next-generation advanced reactors (see e.g., Bagger et al., 1994; Fuketa et al., 2001; Inoue et al., 2004; Suzuki et al., 2006). Inoue et al. (2004) studied fuel-to-cladding gap evolution and its impact on thermal performance of high burn-up uranium-plutonium oxide fuel pins by one-dimensional steady state thermal analysis. Recently, Suzuki et al. (2006) developed a computer code based on finite element method to analyze high burn-up fuel rod behaviors in the reactivity initiated accident (RIA) conditions.

Lumped parameter models have been widely used in the thermo-hydraulic analysis of nuclear reactors. As in the analysis of other complex thermal systems, this classical approach is extremely useful and sometimes even mandatory when a simplified formulation of the transient heat conduction is sought.

\footnotetext{
* Corresponding author. Tel.: +55 212562 8448; fax: +55 2125628444 .

E-mail addresses: auro@cnen.gov.br (A.C. Pontedeiro), cotta@serv.com. ufrj.br (R.M. Cotta), sujian@con.ufrj.br (J. Su).
}

Together with the neutron point kinetics model, the lumped parameter approach for fuel rod heat conduction is essential in the simplified models of pressurized water reactors (PWRs) and in real-time simulators of nuclear power plants (Zanobetti, 1989). It is of great technological interests to develop lumped models for thermal analysis of high burn-up nuclear fuel rods.

The classic lumped system approach has been widely used in thermal analysis of engineering problems, when simplified solutions of transient heat conduction are sought. As an inherent limitation of the lumped parameter approach, moderate to low temperature gradients within the region are assumed, which govern the accuracy of such approximate formulations through the associated problem parameters. As a rule of thumb, the classical lumped parameter approach that assumes uniform temperature within the domain is in general limited to problems with Biot numbers less than 0.1. In applications where the assumption of moderate to low temperature gradients is not reasonable, a more accurate approach should be adopted.

Cotta and Mikhailov (1998) presented a systematic formalism to provide improved lumped parameter formulations for 
steady and transient heat conduction problems, based on Hermite approximations for integrals (Mennig et al., 1983) that define average temperatures and heat fluxes, as functions of the dependent variable and its derivatives at the boundaries. This formalism has been applied in a variety of heat conduction and convection problems (Aparecido and Cotta, 1989; Scofano Neto and Cotta, 1993; Corrêa and Cotta, 1998; Su, 2001, 2004; Ruperti et al., 2004; Pontedeiro et al., 2004).

Transient heat conduction in a nuclear fuel rod is a typical example where the Biot number is higher than the limit utilized in the classic lumped formulation. Regis et al. (2000) have proposed an improved lumped parameter model for the transient heat conduction in a nuclear fuel rod where the one-sided corrected trapezoidal rule was employed in the averaged temperature integral for the fuel, and the plain trapezoidal rule was used in the averaged temperature integral for the cladding and the heat fluxes $\left(H_{1,0} / H_{0,0}\right.$ approximation). Su and Cotta (2001) presented a higher order lumped parameter analysis in which the two-sided corrected trapezoidal rule was used in the averaged temperature integrals for the fuel and the cladding, and the plain trapezoidal rule was used in the averaged heat flux integrals $\left(H_{1,1} / H_{0,0}\right.$ approximation). The proposed mathematical model was applied to simulate transient neutronic and thermo-hydraulic behavior of the PWR core and the primary circuit of a nuclear power plant during reactivity insertion and partial loss-of-flow transients.

The aim of this work is to develop an improved lumped-differential formulation for transient heat conduction in a heat generating cylinder with temperature-dependent thermo-physical properties. After presenting the mathematical formulation and the improved lumped formulation based on Hermite approximation for integrals, we consider a special case of the transient temperature behavior in a $\mathrm{UO}_{2}$ nuclear fuel rod with the temperature-dependent properties (thermal conductivity, density and specific heat) given by the correlations from MATPRO - a Library of Materials Properties for LightWater-Reactor Accident Analysis (INEL, 1993). An improved lumped model based on two-points Hermite approximations to the average temperature and to the heat flux in the fuel rod is developed ( $H_{1,1} / H_{1,1}$ approximation). The solution of the proposed improved lumped models is then validated by a numerical solution of the original distributed parameter formulation.

\section{Mathematical formulation}

\subsection{One-dimensional transient heat conduction equation}

We consider one-dimensional transient heat conduction in a heat generating cylinder with temperature-dependent thermophysical properties. The material is considered to be homogeneous and isotropic. The mathematical formulation governing the physical problem is written as follows:

$\rho(T) C_{p}(T) \frac{\partial T(r, t)}{\partial t}=\frac{1}{r} \frac{\partial}{\partial r}\left(r k(T) \frac{\partial T(r, t)}{\partial r}\right)+g(t)$ where $T$ is the temperature, $r$ is the radial coordinate, $t$ is the time, $\rho$ is the density, $C_{p}$ is the specific heat, $k$ is the thermal conductivity, and $g$ is the spatially uniform volumetric heat generation rate which is independent of the temperature.

The heat conduction equation (1) is to be solved with appropriate boundary and initial conditions:

$\left.\frac{\partial T(r, t)}{\partial r}\right|_{r \rightarrow 0}=0$

$\left.\frac{\partial T(r, t)}{\partial r}\right|_{r \rightarrow r_{1}}=\frac{h_{\mathrm{ef}}\left(T_{\mathrm{m}}(t)-T\left(r_{1}, t\right)\right)}{k(T)}$

$T(r, 0)=T I(r)$

where $r_{1}$ is the radius of the fuel rod, $h_{\mathrm{ef}}$ is an effective heat transfer coefficient between the heat generating cylinder and the surrounding fluid, and $T_{\mathrm{m}}(t)$ is the time-varying temperature of the surrounding fluid. The effect of the cladding and the gap in heat conduction is represented by the effective heat transfer coefficient that includes the thermal resistance of the cladding, the gap and the heat transfer between the cladding and the coolant.

\subsection{Improved lumped formulation}

The spatially averaged temperature in the fuel rod is defined as

$T_{\mathrm{av}}(t)=\frac{2}{r_{1}^{2}} \int_{0}^{r_{1}} r T(r, t) \mathrm{d} r$

and thus

$\frac{\mathrm{d} T_{\mathrm{av}}(t)}{\mathrm{d} t}=\frac{2 \int_{0}^{r_{1}} r(\partial T(r, t) / \partial t) \mathrm{d} r}{r_{1}^{2}}$

We operate Eq. (1) with $2 \int_{0}^{r_{1}} r \mathrm{~d} r / r_{1}^{2}$ and use the average temperature defined in Eq. (5):

$\frac{2}{r_{1}^{2}} \int_{0}^{r_{1}}\left(r C_{p}(T) \rho(T) \frac{\partial T(r, t)}{\partial t}\right) \mathrm{d} r$

$=\frac{2}{r_{1}^{2}} \int_{0}^{r_{1}} r\left(\frac{1}{r} \frac{\partial}{\partial r}\left(r k(T) \frac{\partial T(r, t)}{\partial r}\right)+g(t)\right) \mathrm{d} r$

\subsection{Heat conduction in a nuclear fuel rod}

Now we proceed to analyze transient heat conduction in a nuclear fuel rod made of $\mathrm{UO}_{2}$ ceramic material. The MATPRO correlations (INEL, 1993) for the thermo-physical properties of $\mathrm{UO}_{2}$ ceramic material are as follows:

$k(T)=\frac{1}{a+b T(r, t)}+c \frac{\mathrm{e}^{-(d / T(r, t))}}{T(r, t)^{2}}$ 


$$
\begin{aligned}
C_{p}(T)= & \frac{k_{1} \theta^{2} \mathrm{e}^{(\theta / T(r, t))}}{T^{2}(r, t)\left(\mathrm{e}^{(\theta / T(r, t))}-1\right)^{2}}+k_{2} T(r, t) \\
& +\frac{k_{3} \mathrm{EE}_{\mathrm{dd}}}{R T^{2}(r, t)} \mathrm{e}^{-\left(\mathrm{EE}_{\mathrm{dd}} / R T(r, t)\right)}
\end{aligned}
$$

$$
\rho(T)=\rho_{0}\left(1-3\left(K_{1} T(r, t)-K_{2}+K_{3} \mathrm{e}^{-\left(E_{1} / K_{\mathrm{B}} T(r, t)\right)}\right)\right)
$$

where $a=0.0375, \quad b=2.165, \quad c=4.75, \quad$ and $d=16,361$; $k_{1}=296.7, \theta=535.285, k_{2}=2.43 \times 10^{-2}, k_{3}=8.745 \times 10^{7}$, $\mathrm{EE}_{\mathrm{dd}}=1.577 \times 10^{5}$ and $R=8.3143 ; K_{1}=10^{-5}, K_{2}=3.0 \times$ $10^{-3}, K_{3}=4.0 \times 10^{-2}, K_{\mathrm{B}}=1.38 \times 10^{-23}, E_{1}=6.9 \times 10^{-20}$ and $\rho_{0}=10980.0$.

Fig. 1 shows the thermal conductivity of $\mathrm{UO}_{2}$ ceramic material as a function of temperature, given by Eq. (8).

As the product $\rho C_{p}$ has a rather small variation in the temperature range between 500 and $2000 \mathrm{~K}$, as shown in Fig. 2, it is possible to write Eq. (7) using $\rho\left(T_{\mathrm{av}}\right)$ and $C_{p}\left(T_{\mathrm{av}}\right)$, as

$$
\begin{aligned}
& \frac{2 C_{p}\left(T_{\mathrm{av}}\right) \rho\left(T_{\mathrm{av}}\right)}{r_{1}^{2}} \int_{0}^{r_{1}} r \frac{\partial T(r, t)}{\partial t} \mathrm{~d} r \\
& =\frac{2}{r_{1}^{2}} \int_{0}^{r_{1}} r\left(\frac{1}{r} \frac{\partial}{\partial r}\left(r k(T) \frac{\partial T(r, t)}{\partial r}\right)+g(t)\right) \mathrm{d} r
\end{aligned}
$$

From Eqs. (6) and (11), and using the boundary condition, Eq. (3), we have

$\frac{\mathrm{d} T_{\mathrm{av}}(t)}{\mathrm{d} t}=\frac{g(t)+\left(2 h_{\mathrm{ef}} / r_{1}\right)\left(T_{\mathrm{m}}(t)-T\left(r_{1}, t\right)\right)}{\rho\left(T_{\mathrm{av}}\right) C_{p}\left(T_{\mathrm{av}}\right)}$

Eq. (12) is an equivalent integro-differential formulation of the original distributed parameter formulation, Eqs. (1)-(4). Assuming that the temperature gradient is sufficiently smooth over the whole spatial solution domain, the classical lumped system analysis (CLSA) is based on the assumption that the boundary temperatures can be reasonably well approximated by the average temperature.

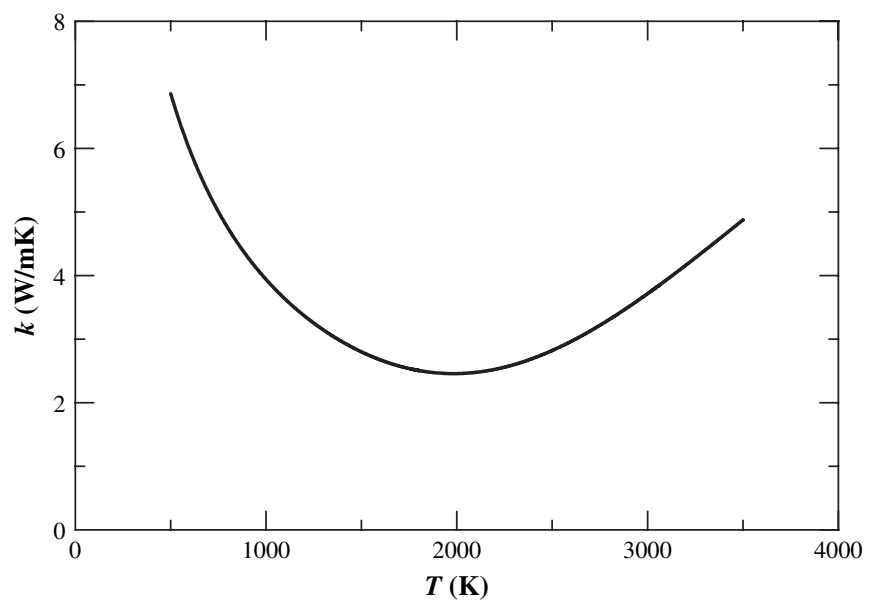

Fig. 1. The temperature dependence of the thermal conductivity of the $\mathrm{UO}_{2}$ ceramic material.

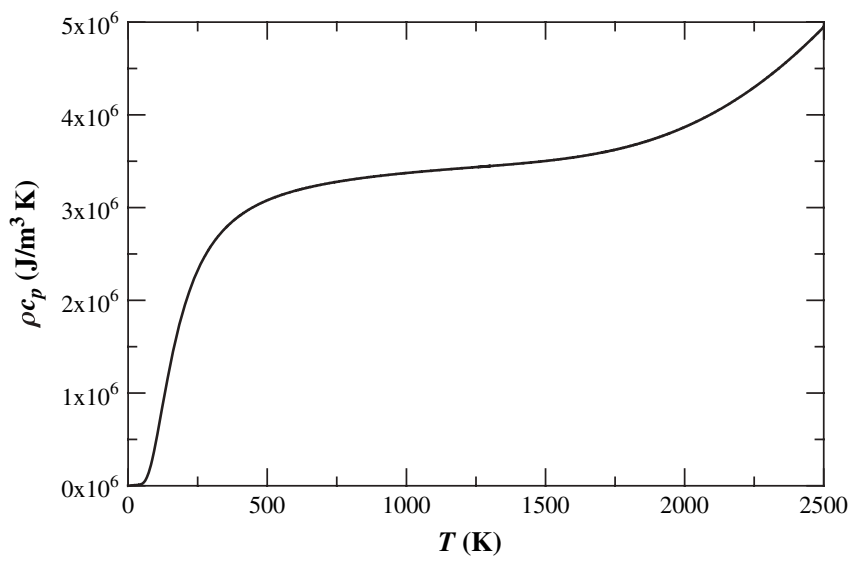

Fig. 2. The temperature dependence of the specific heat capacity $\left(\rho C_{p}\right)$ of the $\mathrm{UO}_{2}$ ceramic material.

$\frac{\mathrm{d} T_{\mathrm{av}}(t)}{\mathrm{d} t}=\frac{g(t)+\left(2 h_{\mathrm{ef}} / r_{1}\right)\left(T_{\mathrm{m}}(t)-T_{\mathrm{av}}(t)\right)}{\rho\left(T_{\mathrm{av}}(t)\right) c_{p}\left(T_{\mathrm{av}}(t)\right)}$

We now seek an improved lumped model, in an attempt to offer enhancement to the approximation approach of the classical lumped model. The basic idea of the improved lumpeddifferential approach is to provide reasonably accurate relations between the boundary fluxes and the averaged temperatures, which are to be developed from two point Hermite approximations for the integrals that define the average temperatures and heat fluxes (Cotta and Mikhailov, 1998; Mennig et al., 1983).

Applying the $H_{1,1} / H_{1,1}$ Hermite formulation both to the average temperature and the heat flux, we have

$T_{\mathrm{av}}(t)=\frac{k\left(T\left(r_{1}, t\right)\right)\left(T(0, t)+5 T\left(r_{1}, t\right)\right)+r_{1} h_{\mathrm{ef}}\left(T\left(r_{1}, t\right)-T_{\mathrm{m}}(t)\right)}{6 k\left(T\left(r_{1}, t\right)\right)}$

$$
\begin{aligned}
T\left(r_{1}, t\right)-T(0, t)= & \frac{r_{1}}{2} \frac{\partial T(0, t)}{\partial r}+\frac{r_{1}}{2} \frac{\partial T\left(r_{1}, t\right)}{\partial r}+\frac{r_{1}^{2}}{12} \frac{\partial^{2} T(0, t)}{\partial r^{2}} \\
& -\frac{r_{1}^{2}}{12} \frac{\partial^{2} T\left(r_{1}, t\right)}{\partial r^{2}}
\end{aligned}
$$

where

$$
\begin{aligned}
\frac{\partial^{2} T(0, t)}{\partial r^{2}}= & \frac{-g(t)+\rho\left(T_{\mathrm{av}}\right) C_{p}\left(T_{\mathrm{av}}\right)(\partial T(0, t) / \partial t)}{2 k(T(0, t))} \\
\frac{\partial^{2} T\left(r_{1}, t\right)}{\partial r^{2}}= & \frac{1}{r_{1} k\left(T\left(r_{1}, t\right)\right)^{3}}\left(h _ { \mathrm { ef } } \left(T\left(r_{1}, t\right)-r_{1} g(t) k\left(T\left(r_{1}, t\right)\right)^{2}\right.\right. \\
& \left.-T_{\mathrm{m}}(t)\right)\left(k\left(T\left(r_{1}, t\right)\right)^{2}+r_{1} h_{\mathrm{ef}}\left(-T\left(r_{1}, t\right)\right.\right. \\
& \left.\left.+T_{\mathrm{m}}(t)\right)\right) \frac{\mathrm{d} k\left(T\left(r_{1}, t\right)\right)}{\mathrm{d} T} \\
& \left.+r_{1} k\left(T\left(r_{1}, t\right)\right)^{2} \rho\left(T_{\mathrm{av}}\right) C_{p}\left(T_{\mathrm{av}}\right) \frac{\partial T\left(r_{1}, t\right)}{\partial t}\right)
\end{aligned}
$$




$$
\begin{aligned}
C_{p}\left(T_{\mathrm{av}}\right)= & \frac{k_{1} \theta^{2} \mathrm{e}^{\left(\theta / T_{\mathrm{av}}(t)\right)}}{T_{\mathrm{av}}^{2}(t)\left(\mathrm{e}^{\left(\theta / T_{\mathrm{av}}(t)\right)}-1\right)^{2}} \\
& +k_{2} T_{\mathrm{av}}(t)+\frac{k_{3} \mathrm{EE}_{\mathrm{dd}}}{R T_{\mathrm{av}}^{2}(t)} \mathrm{e}^{-\left(\mathrm{EE}_{\mathrm{dd}} / R T_{\mathrm{av}}(t)\right)} \\
\rho\left(T_{\mathrm{av}}\right)= & \rho_{0}\left(1-3\left(K_{1} T_{\mathrm{av}}(t)-K_{2}+K_{3} \mathrm{e}^{-\left(E_{1} / K_{\mathrm{B}} T_{\mathrm{av}}(t)\right)}\right)\right)
\end{aligned}
$$

$$
\begin{aligned}
& Y_{1}=\frac{r_{1}^{2}\left(-g(t)+\rho\left(T_{\mathrm{av}}\right) C_{p}\left(T_{\mathrm{av}}\right)\right)(\partial T(0, t) / \partial t)}{24\left(\left(c \mathrm{e}^{-(d / T(0, t))} / T(0, t)^{2}\right)+(1 /(a+b T(0, t)))\right)} \\
& Z_{1}=r_{1} \rho\left(T_{\mathrm{av}}\right) C_{p}\left(T_{\mathrm{av}}\right) \frac{\partial T\left(r_{1}, t\right)}{\partial t}
\end{aligned}
$$

$$
X_{2}=\frac{r_{1} h_{\mathrm{ef}}\left(T\left(r_{1}, t\right)-T_{\mathrm{m}}(t)\right)\left(\left(c \mathrm{e}^{-\left(d / T\left(r_{1}, t\right)\right)} / T\left(r_{1}, t\right)^{4}\right)-\left(2 c \mathrm{e}^{-\left(d / T\left(r_{1}, t\right)\right)} / T\left(r_{1}, t\right)^{3}\right)-\left(1 /\left(a+b T\left(r_{1}, t\right)\right)^{2}\right)\right)}{\left(c \mathrm{e}^{-\left(d / T\left(r_{1}, t\right)\right)} / T\left(r_{1}, t\right)^{2}\right)+\left(1 /\left(a+b T\left(r_{1}, t\right)\right)\right)}
$$

$k(T(0, t))=\frac{c \mathrm{e}^{-(d / T(0, t))}}{T(0, t)^{2}}+\frac{1}{a+b T(0, t)}$

$k\left(T\left(r_{1}, t\right)\right)=\frac{c \mathrm{e}^{-\left(d / T\left(r_{1}, t\right)\right)}}{T\left(r_{1}, t\right)^{2}}+\frac{1}{a+b T\left(r_{1}, t\right)}$

The thermal conductivity derivative for $T\left(r_{1}, t\right)$ is

$\frac{\mathrm{d} k\left(T\left(r_{1}, t\right)\right)}{\mathrm{d} T}=\frac{c d \mathrm{e}^{-\left(d / T\left(r_{1}, t\right)\right)}}{T\left(r_{1}, t\right)^{4}}-\frac{2 c \mathrm{e}^{-\left(d / T\left(r_{1}, t\right)\right)}}{T\left(r_{1}, t\right)^{3}}-\frac{b}{\left(a+b T\left(r_{1}, t\right)\right)^{2}}$

In order to construct the system of equations to be solved, we need to define two ordinary differential equations and two initial conditions. The first equation is obtained by substituting Eqs. (14), (16)-(22) and the boundary conditions, Eqs. (2) and (3), into Eq. (15). By this way we can eliminate $T_{\mathrm{av}}$, getting Eq. (23), as a function of $T(0, t), T\left(r_{1}, t\right),(\partial T(0, t) / \partial t)$, $\left(\partial T\left(r_{1}, t\right) / \partial t\right)$ :

$$
\begin{aligned}
& T\left(r_{1}, t\right)-T(0, t) \\
& =X_{1}+Y_{1}-\frac{r_{1}\left(h_{\mathrm{ef}}\left(T\left(r_{1}, t\right)-r_{1} g(t)-T_{\mathrm{m}}(t)\right)+X_{2}+Z_{1}\right)}{X_{3}}
\end{aligned}
$$

where

$$
X_{1}=-\frac{r_{1} h_{\mathrm{ef}}\left(T\left(r_{1}, t\right)-T_{\mathrm{m}}(t)\right)}{2\left(\left(c \mathrm{e}^{-\left(d / T\left(r_{1}, t\right)\right)} / T\left(r_{1}, t\right)^{2}\right)+\left(1 /\left(a+b T\left(r_{1}, t\right)\right)\right)\right)}
$$

$$
X_{3}=12\left(\frac{c \mathrm{e}^{-\left(d / T\left(r_{1}, t\right)\right)}}{T\left(r_{1}, t\right)^{2}}+\frac{1}{a+b T\left(r_{1}, t\right)}\right)
$$

The second differential equation can be obtained by operating both sides of Eq. (14), using differentiation in time, and combining it with Eq. (12), in order to eliminate $T_{\mathrm{av}}$.

By this way, we can eliminate $T_{\mathrm{av}}$, substituting Eq. (14) into Eq. (24), as a function of $T(0, t), T\left(r_{1}, t\right),\left(\partial T\left(r_{1}, t\right) / \partial t\right)$ :

$$
\frac{\partial T\left(r_{1}, t\right)}{\partial t}=\frac{P+Q}{M+S+V}
$$

where

$$
P=\frac{g(t)+\left(2 h_{\mathrm{ef}}\left(-T\left(r_{1}, t\right)+T_{\mathrm{m}}(t)\right) / r_{1}\right)}{\rho_{0}\left(P_{1}+k_{2} T_{\mathrm{av}}(t)\right)\left(1-3\left(-K_{2}+\mathrm{e}^{-\left(E_{1} / K_{\mathrm{B}} T_{\mathrm{av}}(t)\right)} K_{3}+K_{1} T_{\mathrm{av}}(t)\right)\right)}
$$

$$
P_{1}=\frac{\mathrm{e}^{\left(\theta / T_{\mathrm{av}}(t)\right)} \theta^{2} k_{1}}{\left(-1+\mathrm{e}^{\left(\theta / T_{\mathrm{av}}(t)\right)}\right)^{2} T_{\mathrm{av}}(t)^{2}}+\frac{\mathrm{e}^{-\left(\mathrm{EE}_{\mathrm{dd}} / R T_{\mathrm{av}}(t)\right)} \mathrm{EE}_{\mathrm{dd}} k_{3}}{R T_{\mathrm{av}}(t)^{2}}
$$

$$
\begin{aligned}
Q= & \frac{r_{1} h_{\mathrm{ef}}\left(\mathrm{d} T_{\mathrm{m}}(t) / \mathrm{d} t\right)}{4\left(\left(c \mathrm{e}^{-\left(d / T\left(r_{1}, t\right)\right)} / T\left(r_{1}, t\right)^{2}\right)+\left(1 /\left(a+b T\left(r_{1}, t\right)\right)\right)\right)^{2}} \\
& \times\left[\frac{c \mathrm{e}^{-\left(d / T\left(r_{1}, t\right)\right)}}{T\left(r_{1}, t\right)^{2}}+\frac{1}{\left(a+b T\left(r_{1}, t\right)\right)}\right]
\end{aligned}
$$

$$
\begin{aligned}
& M=\frac{\mathrm{e}^{-\left(2 d / T\left(r_{1}, t\right)\right)}\left(a c+b c T\left(r_{1}, t\right)+\mathrm{e}^{\left(d / T\left(r_{1}, t\right)\right)} T\left(r_{1}, t\right)^{2}\right)^{2}}{T\left(r_{1}, t\right)^{4}\left(a+b T\left(r_{1}, t\right)\right)^{2}\left[\left(c \mathrm{e}^{-\left(d / T\left(r_{1}, t\right)\right)} / T\left(r_{1}, t\right)^{2}\right)+\left(1 /\left(a+b T\left(r_{1}, t\right)\right)\right)\right]^{2}} \\
& S=\frac{r_{1} h_{\mathrm{ef}}\left(a+2 b T\left(r_{1}, t\right)-b T_{\mathrm{m}}(t)\right)}{4\left(a+b T\left(r_{1}, t\right)\right)^{2}\left[\left(c \mathrm{e}^{-\left(d / T\left(r_{1}, t\right)\right)} / T\left(r_{1}, t\right)^{2}\right)+\left(1 /\left(a+b T\left(r_{1}, t\right)\right)\right)\right]^{2}}
\end{aligned}
$$




$$
V=\frac{c \mathrm{e}^{-\left(d / T\left(r_{1}, t\right)\right)} r_{1} h_{\mathrm{ef}}\left(3 T\left(r_{1}, t\right)^{2}+d T_{\mathrm{m}}(t)-T\left(r_{1}, t\right)\left(d+2 T_{\mathrm{m}}(t)\right)\right)}{4 T\left(r_{1}, t\right)^{4}\left[\left(c \mathrm{e}^{-\left(d / T\left(r_{1}, t\right)\right)} / T\left(r_{1}, t\right)^{2}\right)+\left(1 /\left(a+b T\left(r_{1}, t\right)\right)\right)\right]^{2}}
$$

The above system allows us to obtain the transient temperature at the center and at the outer surface of the fuel rod $\left(T(0, t)\right.$ and $\left.T\left(r_{1}, t\right)\right)$. Then, if required, $T_{\mathrm{av}}(t)$ can be evaluated from Eq. (14).

\section{Results and discussion}

In order to evaluate the accuracy of the improved lumped model proposed in this work, we have carried out a comparative study of transient heat conduction in a cylindrical nuclear fuel rod using the classical lumped model, Eq. (13), the improved lumped model and the original distributed parameter model, Eqs. (1)-(4). The numerical results obtained by the classical lumped model and the improved lumped model $H_{11}-H_{11}$ are compared with the results obtained by a numerical solution of the original distributed parameter formulation, using the built-in function of MATHEMATICA NDSolve (Wolfram, 1999). The MATPRO correlations (INEL, 1993) for the thermo-physical properties of $\mathrm{UO}_{2}$ ceramic material given in Eqs. (8)-(10) are used in all test examples.

\subsection{Example $1(0.09<B i<0.29)$}

The first numerical example, chosen for validation purposes, utilizes values for the fuel material properties according to Eqs. (8)-(10) and the system formed by Eqs. (22), (23) and (13) solved with the following conditions: $h_{\mathrm{ef}}=130.0 \mathrm{~W} / \mathrm{m}^{2} \mathrm{~K} ; r_{1}=0.0045 \mathrm{~m} ; T_{\mathrm{m}}=613.15 \mathrm{~K} ; T(0,0)=$ $T\left(r_{1}, 0\right)=613.15 \mathrm{~K} ; g(t)=0.0$ if $t<20 \mathrm{~s} ; g(t)=628.7603 \mathrm{~W} /$ $\mathrm{m}^{3}$. The Biot number $B i\left(=h_{\mathrm{ef}} r_{1} / k\right)$ varies between 0.09 and 0.29 due to the variation of the heat conductivity with the temperature.

Table 1 shows the relative errors of the average, center and surface temperatures calculated by the classical and improved lumped models when compared with the reference numerical

Table 1

Relative errors of the classical and improved lumped models

\begin{tabular}{llll}
\hline Time $(\mathrm{s})$ & Temperature & CLSA & $H_{1,1}-H_{1,1}$ \\
\hline 4 & $T_{\mathrm{av}}$ & 1.9 & 0.3 \\
& $T_{\mathrm{c}}$ & & 0.7 \\
& $T_{\mathrm{w}}$ & & 0.5 \\
50 & $T_{\mathrm{av}}$ & 1.5 & 0.0 \\
& $T_{\mathrm{c}}$ & & 0.0 \\
& $T_{\mathrm{w}}$ & & 0.0 \\
100 & $T_{\mathrm{av}}$ & 1.1 & 0.0 \\
& $T_{\mathrm{c}}$ & & 0.1 \\
& $T_{\mathrm{w}}$ & & 0.0 \\
300 & $T_{\mathrm{av}}$ & 0.8 & 0.0 \\
& $T_{\mathrm{c}}$ & & 0.0 \\
& $T_{\mathrm{w}}$ & & 0.0 \\
\hline
\end{tabular}

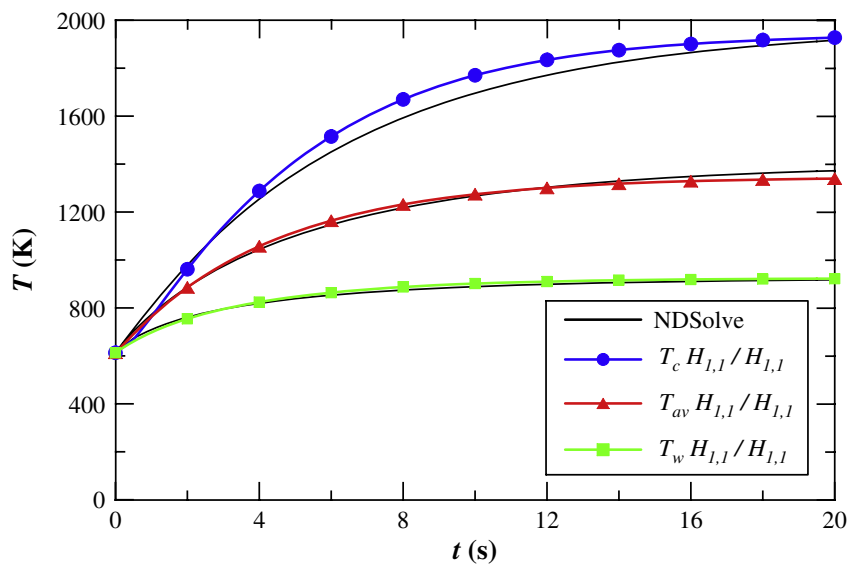

Fig. 3. Comparison of the improved lumped models and numerical solution of the distributed parameter model for constant heat generation rate.

solution obtained by NDSolve, for the times of 4, 50, 100, and $300 \mathrm{~s}$. It can be seen that all calculated relative errors are less than $2 \%$, showing the good performance of both lumped models for Biot numbers between 0.09 and 0.29.

\subsection{Example $2(3<B i<10)$}

The second numerical example also utilizes values for the fuel material properties according to Eqs. (8)-(10). A representative heat transfer coefficient for a PWR fuel rod is used: $h_{\mathrm{ef}}=4540.0 \mathrm{~W} / \mathrm{m}^{2} \mathrm{~K}$, which corresponds to Biot numbers between 3 and 10, due to the variation of the heat conductivity with the temperature.

Again, the numerical results obtained by the improved lumped system $H_{1,1} / H_{1,1}$ are compared with the results obtained by a numerical solution of the original distributed parameter formulation, using NDSolve, as shown in Figs. 3 and 4. Fig. 3 shows the temperature evolution predicted by the improved lumped model $H_{1,1} / H_{1,1}$ for the first $20 \mathrm{~s}$ of the transient compared with numerical solution by NDSolve. Fig. 4 shows typical results of a slow transient in which the

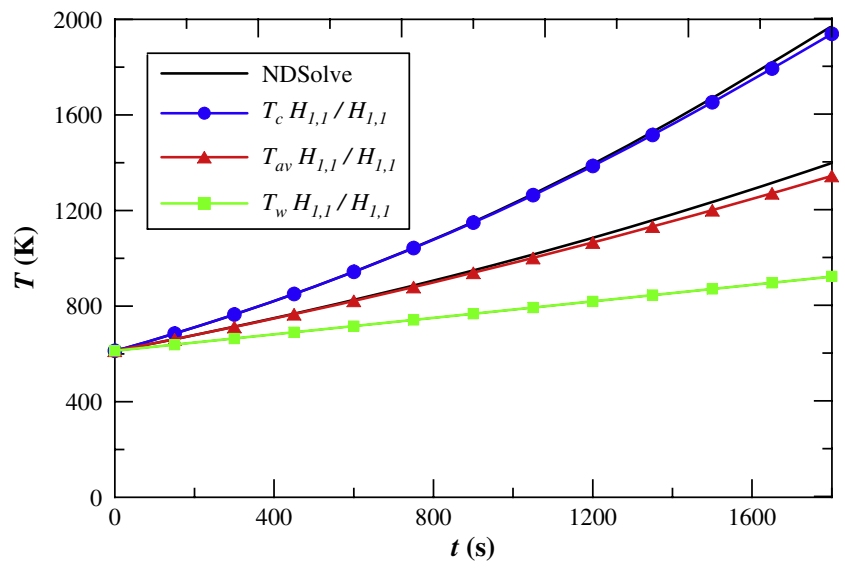

Fig. 4. Comparison of the improved lumped models and numerical solution of the distributed parameter model for a slow transient of linear power rise. 
Table 2

The event sequence of a cold leg SBLOCA

\begin{tabular}{ll}
\hline Time (s) & Main events \\
\hline 20 & Start of leakage \\
$\sim 32$ & Reactor shutdown \\
$\sim 595$ & Cladding dryout \\
\hline
\end{tabular}

reactor power rises linearly during the first $30 \mathrm{~min}$. It can be seen that the solution of the improved lumped model agrees very well with the numerical solution.

\subsection{Example 3: SBLOCA in a cold leg of NPP Angra 2}

In the following example, we simulated a Small Break Loss of Coolant Accident (SBLOCA) in a cold leg of the Brazilian Nuclear Power Plant Angra 2, based on simulation data obtained by Madeira et al. (2007) using RELAP5/MOD3. The sequence of events until the occurrence of dryout is given in Table 2. Beyond this point, the present model is no longer applicable as the fuel rod cladding must be modeled separately.

Fig. 5 shows the curve of the normalized reactor power during $800 \mathrm{~s}$ and Fig. 6 shows the average coolant temperature in the reactor core during the same period. The heat generation rate in the fuel rod was first adjusted to obtain the core power output level of the RELAP simulation. Second, a period of $20 \mathrm{~s}$ was used for the model to reach the steady state from which the sequence of events starts. As shown in Figs. 5 and 6 , the leakage starts at $20 \mathrm{~s}$ with the coolant temperature rises until $32 \mathrm{~s}$ when the reactor is shutdown. From this instant forward the reactor power begins to drop, as well as the coolant and fuel temperatures. It can be seen that few minutes after the reactor shutdown the residual power is already less than $1 \%$ of the full power level. Correspondingly, the coolant temperature drops very quickly. Fig. 7 shows the results of the temperature at the center of the fuel rod compared with the simulation results by RELAP5 which uses a finite difference method. The same correlations of thermo-physical properties have been used in both simulations. An excellent agreement between

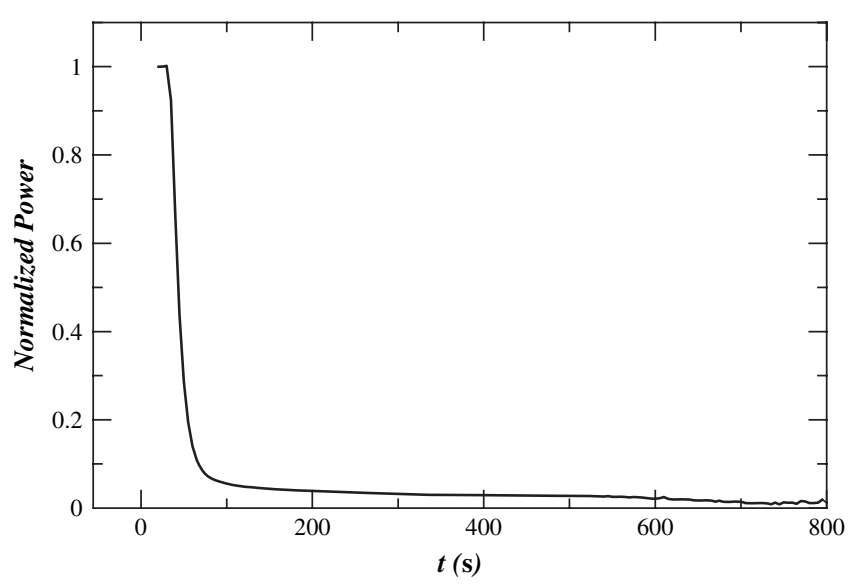

Fig. 5. Normalized reactor power of NPP Angra 2 during a cold leg SBLOCA given by RELAP5 simulation.

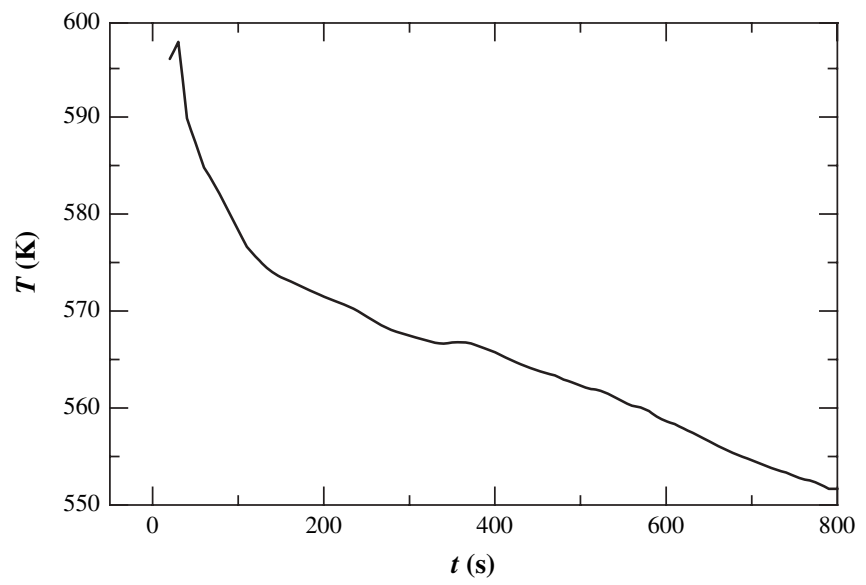

Fig. 6. Average coolant temperature in the reactor core of NPP Angra 2 during a cold leg SBLOCA given by RELAP5 simulation.

the solutions by improved lumped model and the RELAP5 simulation can be observed until the occurrence of dryout after which the RELAP5 simulation predicts a rapid rise of the fuel temperature.

\section{Conclusions}

It was shown in this paper that the improved lumped parameter formulation could be an interesting alternative approximate methodology to simulate the temperature transients in a nuclear fuel rod. It was useful to analyze the behavior of the improved lumped approach in predicting nuclear fuel rod temperature transient, especially with respect to the fuel centerline temperature, which is an important criterion for nuclear reactors design. By using the simplified model with density and specific heat as a function of the average temperature the results provided by the improved lumped model were quite good to $\mathrm{UO}_{2}$ ceramic material. The possibility of applying this approach to a situation with temperature-dependent thermal properties, still with reasonably accurate results, confirms that the improved lumped parameter formulation might be

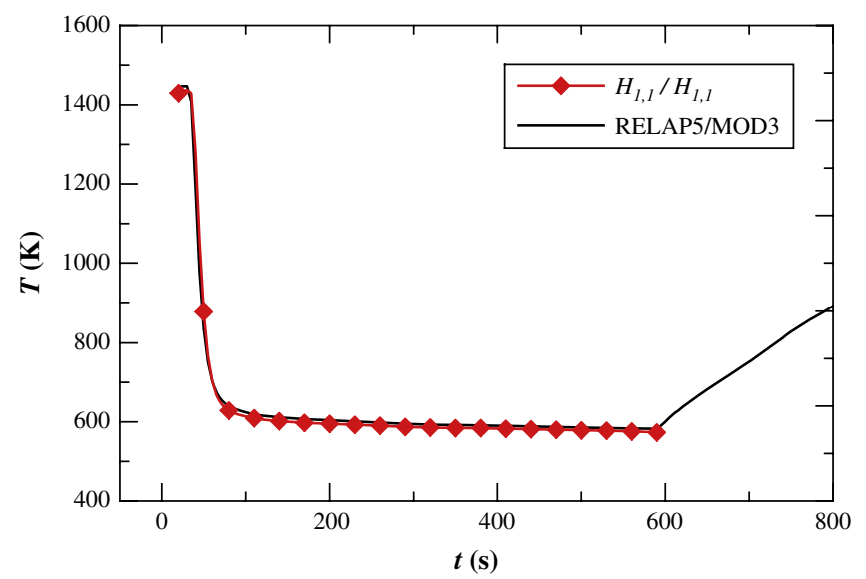

Fig. 7. Comparison of the temperature in the fuel rod center during a cold leg SBLOCA given by ILSA $H_{1,1}-H_{1,1}$ model and RELAP5 simulation. 
very useful for design, safety analysis and plant simulators of nuclear reactors.

\section{Acknowledgement}

The authors acknowledge gratefully the financial support by CNPq, CAPES and FAPERJ during the realization of this work.

\section{References}

Aparecido, J.B., Cotta, R.M., 1989. Modified one-dimensional fin solutions. Heat Transfer Eng. 11, 49-59.

Bagger, C., Mogensen, M., Walker, C.T., 1994. Temperature measurements in high burn-up $\mathrm{UO}_{2}$ nuclear fuel: implications for thermal conductivity grain growth and gas release. J. Nucl. Mater. 211, 11-29.

Corrêa, E.J., Cotta, R.M., 1998. Enhanced lumped-differential formulations of diffusion problems. Appl. Math. Modell. 22, 137-152.

Cotta, R.M., Mikhailov, M.D., 1998. Heat Conduction - Lumped Analysis, Integral Transforms, Symbolic Computation. John Wiley \& Sons, Chichester.

Fuketa, T., Sasajima, H., Sugiyama, T., 2001. Behavior of high-burnup PWR fuels with low-tin Zircaloy-4 cladding under reactivity-initiated-accident conditions. Nucl. Technol. 133, 50.

INEL, 1993. MATPRO - A library of materials properties for light-waterreactor accident analysis, NUREG/CR-6150, EGG-2720, vol. IV. Idaho National Engineering Laboratory, Idaho, USA.

Inoue, M., Maeda, K., Katsuyama, K., Tanaka, K., Mondo, K., Hisada, M., 2004. Fuel-to-cladding gap evolution and its impact on thermal performance of high burnup fast reactor type uranium-plutonium oxide fuel pins. J. Nucl. Mater. 326, 59-73.

Madeira, A.A., Pereira, L.C.M., Lapa, N.S., 2007. Evaluation of uncertainties in the simulation of accidents in Angra 2 using RELAP5/Mod3 code applying CIAU Italian Methodology, NT-CODRE-02/2007. Comissão Nacional de Energia Nuclear - CNEN.

Mennig, J., Auerbach, T., Hälg, W., 1983. Two point Hermite approximations for the solution of linear initial value and boundary value problems. Comput. Methods Appl. Mech. Eng. 39, 199-224.

Pontedeiro, A.C., Su, J., Cotta, R.M., 2004. Improved lumped model for transient heat conduction in a heat generating cylinder with temperaturedependent thermophysical properties, HT-FED2004-56051. In: Proceedings of 2004 ASME Heat Transfer/Fluids Engineering Summer Conference, Charlotte, North Carolina, USA, 11-15 July.

Regis, C.R., Cotta, R.M., Su, J., 2000. Improved lumped analysis of transient heat conduction in a nuclear fuel rod. Int. Comm. Heat Mass Transfer 27, $357-366$.

Ruperti Jr., N.J., Falkenberg, C.V., Cotta, R.M., Su, J., 2004. Engineering analysis of ablative thermal protection for atmospheric re-entry: improved lumped formulations and symbolic-numerical computation. Heat Transfer Eng. 25 (6), 101-111.

Scofano Neto, F., Cotta, R.M., 1993. Improved hybrid lumped-differential formation for double-pipe heat exchanger analysis. J. Heat Transfer 115, 921-927.

$\mathrm{Su}$, J., 2001. Improved lumped models for asymmetric cooling of a long slab by heat convection. Int. Comm. Heat Mass Transfer 28, 973983.

$\mathrm{Su}$, J., 2004. Improved lumped models for transient radioactive cooling of a spherical body. Int. Comm. Heat Mass Transfer 31, 85-94.

$\mathrm{Su}$, J., Cotta, R.M., 2001. Improved lumped parameter formulation for simplified LWR thermo-hydraulic analysis. Ann. Nucl. Energy 28, 1019-1031.

Suzuki, M., Saitou, H., Fuketa, T., 2006. Analysis on split failure of cladding of high burnup BWR rods in reactivity-initiated accident conditions by RANNS code. Nucl. Eng. Des. 236, 128-139.

Wolfram, S., 1999. The MATHEMATICA Book, fourth ed. Wolfram Media, Cambridge. University Press, UK.

Zanobetti, D., 1989. Power Station Simulators. Elsevier, Amsterdam. 